\title{
Risk factors for decreased bone density in premenopausal women
}

\author{
C. Krahe ${ }^{1}$, \\ R. Friedman ${ }^{2}$ \\ and J.L. Gross ${ }^{2}$
}

\begin{abstract}
'Departamento de Ginecologia e Obstetrícia, Faculdade de Medicina, Pontifícia Universidade Católica do Rio Grande do Sul, Porto Alegre, RS, Brasil

${ }^{2}$ Serviço de Endocrinologia, Departamento de Medicina Interna, Hospital de Clínicas de Porto Alegre, Universidade Federal do Rio Grande do Sul, Porto Alegre, RS, Brasil
\end{abstract}

\section{Correspondence}

J.L. Gross

Serviço de Endocrinologia

Hospital de Clínicas de Porto Alegre

Rua Ramiro Barcelos, 2350, sala 2030

90035-003 Porto Alegre, RS

Brasil

Fax: 55 (051) 332-5188

E-mail: gross@hotnet.net

Received September 12, 1996 Accepted July 16, 1997

\begin{abstract}
Osteoporosis is a major health problem. Little is known about the risk factors in premenopause. Sixty 40-50-year old patients with regular menses were studied cross-sectionally. None of the patients were on drugs known to interfere with bone mass. Patients answered a dietary inquiry and had their bone mineral density (BMD) measured. The $\mathrm{Z}$ scores were used for the comparisons. A blood sample was taken for the determination of FSH, SHBG, estradiol, testosterone, calcium and alkaline phosphatase. Calcium and creatinine were measured in 24-h urine. A Z score less than -1 was observed for the lumbar spine of 14 patients $(23.3 \%)$, and for the femur of 24 patients (40\%). Patients with a Z score less than -1 for the lumbar spine were older than patients with a $\mathrm{Z}$ score $\geq-1$ (45.7 vs 43.8 years) and presented higher values of alkaline phosphatase $(71.1 \pm 18.2$ vs $57.1 \pm 14.3 \mathrm{IU} / \mathrm{l})$. Multiple regression analysis showed that a lower lumbar spine BMD was associated with higher values of alkaline phosphatase, lower calcium ingestion, a smaller body mass index (BMI), less frequent exercising, and older age. The patients with a $\mathrm{Z}$ score less than -1 for the femur were shorter than patients with a $Z$ score $\geq-1(158.2$ vs $161.3 \mathrm{~cm})$. Multiple regression analysis showed that a lower femoral BMD was associated with lower BMI, higher alkaline phosphatase and caffeine intake, and less frequent exercising. A lower than expected BMD was observed in a significant proportion of premenopausal women and was associated with lower calcium intake, relatively lower physical activity and lower BMI. We conclude that the classical risk factors for osteoporosis may be present before ovarian failure, and their effect may be partly independent of estrogen levels.
\end{abstract}

Key words

- Osteoporosis

- Bone loss

- Premenopause

- Osteopenia

- Densitometry

\section{Introduction}

Osteoporosis is a major health problem because it is associated with an increase in fracture rate $(1,2)$. More than 1.5 million Americans are expected to have fractures every year, a cost of about 10 billion dollars $(1,2)$. The disorder affects mainly women after 50 years of age. From the onset of ovarian failure a woman loses 3 to $5 \%$ of her bone mass per year (3). Several other factors are associated with bone loss: low calcium intake, less frequent exercise, smoking and alcohol abuse, certain drugs, and low exposure to sunlight, among others $(4,5)$.

After the detection of osteoporosis, the 
therapeutic options are limited, costly and imply some risk. It is therefore important to detect risk factors for the development of osteoporosis as early as possible (6-8) so that preventive measures can be adopted. Most of the research in this field has been carried out on postmenopausal women and little is known about premenopause. Determinations of bone mineral density (BMD) have been suggested as a method to identify individuals at risk (9). A decrease of 1 SD in BMD significantly increases the risk of fractures by $50 \%$, irrespective of the site where the measurement was taken (9).

Thus, the aim of the present study was to measure BMD in 40-50-year old premenopausal women with normal ovarian function and to determine the factors associated with the disorder.

\section{Patients and Methods}

A cross-sectional study of 60 white women, 40 to 50 years old, with regular menses, was performed. The exclusion criteria were chronic illnesses and current use of estrogen, progesterone, androgen, adrenal steroids, thyroid hormones or any other drugs that might affect bone mass (tamoxifen, diuretics, anticonvulsants, and barbiturates). Patients who had used hormonal contraceptive pills in the past or who had received occasional treatment with estrogen and/or progesterone were not excluded. The protocol was approved by the Ethics Committee of the Hospital de Clínicas de Porto Alegre. Patients were recruited from the private practice of one of the authors (CK). A total of 220 patients aged 40 to 50 years were identified and contacted. Eighty-two agreed to attend a meeting where the protocol was presented, 12 were excluded on the basis of the above criteria, and an additional 10 patients were subsequently excluded for not having concluded the tests.

Patients answered a questionnaire inquiring about their age, smoking habits, physical activity, alcohol consumption over the last 5 years, and knowledge of family history of osteoporosis. Physical activity was analyzed as sports practice, and categorized as "positive", i.e., regularly practiced throughout the year (at least twice a week), or "negative", i.e., all other situations. The following activities were considered to be sports: walking, cycling, swimming, gymnastics, or court sports. A four-day complete dietary inquiry was obtained, and the energy, alcohol, caffeine and calcium intakes were calculated $(10,11)$. Patients were weighed and measured and BMI was reported as $\mathrm{kg} / \mathrm{m}^{2}$. A blood sample was taken between the 5 th and 10th day of the cycle for the determination of FSH (immunoradiometric assay, reference values $5-20 \mathrm{mIU} / \mathrm{ml}$, Irma-Count $\left.{ }^{\circledR}\right)$, SHBG (immunoradiometric assay, $20-130 \mathrm{nmol} / \mathrm{l}$, Irma-Count ${ }^{\circledR}$ ), testosterone (radioimmunoassay, 20-80 ng/dl, COAT-A-COUNT ${ }^{\circledR}$ ), estradiol (radioimmunoassay, 25-150 pg/ml, COAT-A-COUNT ${ }^{\circledR}$ ), calcium (cresolphthalein-complexone method, $8.5-11.0 \mathrm{mg} / \mathrm{dl})$ and alkaline phosphatase (enzymatic method, 35-90 IU/1). Calcium and creatinine (Jaffé's reaction) were measured in $24-\mathrm{h}$ urine samples.

BMD was measured by densitometry (dual-energy X-ray absorptiometry, Lunar DPX-L) for the lumbar spine (L1, L2-L4) and femur (neck, Ward's triangle and trochanter). BMD $\left(\mathrm{g} / \mathrm{cm}^{2}\right)$ was compared to reference standards for young adults, and the $\mathrm{Z}$ scores were calculated accordingly.

For comparison, patients were grouped according to $\mathrm{Z}$ score. Those with a $\mathrm{Z}$ score below -1 (group 1) were compared to those with a $\mathrm{Z}$ score equal to or greater than -1 (group 2). This criterion was used for the lumbar spine (L1 and/or L2-L4) and femur (neck and/or Ward's triangle and/or trochanter separately). For simple comparisons, the Student $t$-test, Wilcoxon-Mann-Whitney test, chi-square test, and Fisher's exact test were used as appropriate. The effect of the different variables on the $\mathrm{Z}$ score was stud- 
ied by stepwise multivariate regression analysis. Taking into account the sample size, the independent variables to be entered into the multivariate analysis were the seven ones more strongly correlated with $\mathrm{Z}$ scores in the univariate analysis, or those with a previously known association with BMD. Results are reported as mean \pm SD (range) or median (range), unless otherwise stated.

\section{Results}

The 60 patients were $44.3 \pm 2.9$ (40-50) years old, weighed $60.2 \pm 10.5(47-90) \mathrm{kg}$, and had a height of $160.1 \pm 6.04$ (142-170) $\mathrm{cm}$, and BMI of $23.5 \pm 3.34(19-34) \mathrm{kg} / \mathrm{m}^{2}$.

The results of the densitometric studies are listed in Table 1. For an expected frequency of about $15.9 \%, 14$ patients $(23.3 \%)$ had at least one $\mathrm{Z}$ score under -1 at the lumbar spine level $\left(\chi^{2}=1.978,0.10<\mathrm{P}<0.25\right)$, and 24 patients $(40 \%)$ had a $\mathrm{Z}$ score under -1 for the femur $\left(\chi^{2}=24.4, \mathrm{P}<0.0001\right)$.

The dietary data are summarized in Table 2. Fifty-two percent of the patients had a daily calcium intake of less than $800 \mathrm{mg}$, which is the minimum recommended daily allowance.

The results of the various hormonal and biochemical parameters are summarized in Table 3. No FSH higher than $40 \mathrm{mIU} / \mathrm{ml}$ or elevated testosterone values were observed. Hypercalcemia was not observed; 18 patients had calciuria $>4 \mathrm{mg} \mathrm{kg}^{-1} 24 \mathrm{~h}^{-1}$. Three patients had alkaline phosphatase $>90 \mathrm{IU} / \mathrm{l}$ (92, 104 and 118 IU/l, respectively).

Thirty-six (60\%) patients had smoked in the past, but only $13(21.7 \%)$ continued to do so. Forty percent began smoking during adolescence. None of the patients smoked more than 10 cigarettes a day.

Less than one quarter of the patients $(21.6 \%)$ exercised regularly, $25 \%$ never practiced any sport, and $53.4 \%$ exercised irregularly.

Twenty-five $(41.6 \%)$ patients reported relatives with osteoporosis; 16 (26.7\%) could not report if someone in the family had the disease.

When lumbar spine $\mathrm{Z}$ score was used as the classification criterion, patients in group 1 had a mean age of 45.7 years and patients in group 2 had a mean age of 43.8 years $(\mathrm{P}=$ 0.029 ); in group 1 , mean alkaline phosphatase was $71.1 \pm 18.2(48.0-118.0) \mathrm{IU} / \mathrm{l} v \mathrm{~s}$ $57.1 \pm 14.3(31.0-104.0) \mathrm{IU} / \mathrm{l}$ in group $2(\mathrm{P}=$ 0.007). The other variables did not show significant differences.

Stepwise multiple regression analysis, with the $\mathrm{Z}$ score for $\mathrm{L} 1$ as the dependent variable, showed that alkaline phosphatase was higher in patients with a lower BMD ( $B$ $=-0.3, P=0.015)$, whereas calcium ingestion $(\beta=0.31, \mathrm{P}=0.015), \mathrm{BMI}(\beta=0.49, \mathrm{P}$

\begin{tabular}{|c|c|c|}
\hline \multicolumn{3}{|c|}{ Data are reported as means \pm SD (range) for 60 subjects. } \\
\hline Region & $\begin{array}{l}\text { Bone mineral density } \\
\left(\mathrm{g} / \mathrm{cm}^{2}\right)\end{array}$ & Z score \\
\hline L1 & $\begin{array}{c}1.128 \pm 0.122 \\
(0.833 \text { to } 1.382)\end{array}$ & $\begin{array}{l}-0.01 \pm 1.03 \\
(-2.47 \text { to } 2.10)\end{array}$ \\
\hline L2-L4 & $\begin{array}{c}1.249 \pm 0.136 \\
(0.926 \text { to } 1.585)\end{array}$ & $\begin{array}{c}0.42 \pm 1.13 \\
(-2.28 \text { to } 3.20)\end{array}$ \\
\hline Neck & $\begin{array}{c}0.929 \pm 0.127 \\
\text { (0.688 to } 1.263)\end{array}$ & $\begin{array}{l}-0.41 \pm 1.05 \\
(-2.43 \text { to } 2.36)\end{array}$ \\
\hline Ward's triangle & $\begin{array}{c}0.856 \pm 0.134 \\
(0.627 \text { to } 1.189)\end{array}$ & $\begin{array}{l}-0.38 \pm 1.04 \\
(-2.18 \text { to } 2.14)\end{array}$ \\
\hline Trochanter & $\begin{array}{c}0.789 \pm 0.109 \\
(0.582 \text { to } 1.135)\end{array}$ & $\begin{array}{r}0.03 \pm 0.99 \\
(-1.89 \text { to } 3.13)\end{array}$ \\
\hline
\end{tabular}

Table 2 - Relevant data obtained from a 4-day dietary inquiry of premenopausal women who participated in the study.

Data are reported as means \pm SD (range) or as median (range) for 60 subjects.

$\begin{array}{ll}\text { Total caloric intake (kcal/day) } & 1738.6 \pm 398.9 \text { (994 to 2967.3) } \\ \text { Fiber (g/day) } & 2.60 \text { (0.54 to } 10.82) \\ \text { Alcohol (g/day) } & 4.61 \text { (0 to } 51.32) \\ \text { Caffeine (mg/day) } & 104.4(0.79 \text { to } 461.7) \\ \text { Calcium (mg/day) } & 775.6 \pm 255.2(235.7 \text { to } 1392.3)\end{array}$


Table 3 - Hormonal and biochemical parameters of premenopausal women who participated in the study.

Data are reported as median (range) for 60 subjects.
$\mathrm{FSH}(\mathrm{mlU} / \mathrm{ml})$

Estradiol $(\mathrm{pg} / \mathrm{ml})$

Testosterone (ng/dl)

Serum calcium (mg/dl)

Calciuria (mg/24 h)

Alkaline phosphatase (IU/I)
5.8 (1.9 to 32.3 )

84.5 (19 to 413 )

22.5 (19 to 45 )

9.35 (8.5 to 10.9 )

177 (20 to 526 )

58.5 (31 to 118 )
$=0.0003)$ and sports practice $(\beta=0.27, \mathrm{P}=$ $0.019)$ were higher in patients with a higher BMD. Age presented a borderline negative association with $\mathrm{BMD}$ at $\mathrm{L} 1(\beta=-0.23, \mathrm{P}=$ $0.064)$. When the $Z$ score for L2-L4 was entered as the dependent variable, the same negative correlation for alkaline phosphatase $(B=-0.30, P=0.024)$, age $(B=-0.26, P=$ $0.044)$, and positive correlation for BMI $(\beta=$ $0.44, \mathrm{P}=0.0011)$ and sports practice $(B=$ $0.25, \mathrm{P}=0.033)$ became evident. Both calcium $(\beta=0.24)$ and caffeine $(\beta=0.25)$ ingestion had a borderline significant positive association with $\mathrm{BMD}$ at this level $(\mathrm{P}=$ 0.071 and $\mathrm{P}=0.066$, respectively).

When the femoral BMD was used as the classification criterion, group 2 patients were taller (mean $161.3 \mathrm{~cm}$ ) than group 1 patients $(158.2 \mathrm{~cm}, \mathrm{P}=0.034)$. The other variables investigated were not significantly different.

Stepwise multiple regression analysis, with the $\mathrm{Z}$ score for the femoral neck as the dependent variable, showed that BMI $(B=$ $0.51, \mathrm{P}=0.0003)$ and caffeine $(\beta=0.32, \mathrm{P}=$ $0.024)$ were positively correlated with $\mathrm{Z}$ score. Alkaline phosphatase showed a borderline negative correlation $(B=-0.20, P=$ 0.089 ), and sports practice showed a borderline positive correlation $(B=0.20, P=0.090)$ with $\mathrm{Z}$ score.

When the Z score for Ward's triangle was entered as the dependent variable, caffeine ingestion $(B=0.35, P=0.022)$ and $\mathrm{BMI}(\beta=$ $0.31, \mathrm{P}=0.034$ ) were positively correlated.
Entering the $\mathrm{Z}$ score for the trochanter as the dependent variable resulted in a positive correlation for the BMI $(\beta=0.39, \mathrm{P}=0.0086)$.

Knowledge of osteoporosis in the family was not entered into the multivariate analysis because 16 patients did not know whether or not they had relatives with osteoporosis. Thus, the large number of missing values would have reduced the power of the analysis.

\section{Discussion}

In a sample of white middle class women in the fifth decade of life with normal menses, $14(23.3 \%)$ presented at least one $\mathrm{Z}$ score lower than -1 at the lumbar spine level, and $24(40 \%)$ of them had a Z score under -1 at the femoral level. The hormonal and biochemical profiles of the patients were within the normal range. The role of oral contraceptives in BMD could not be evaluated because the majority of patients in this sample had used these preparations in intermittent or not recollectable patterns.

BMI was higher in patients with a higher BMD; alkaline phosphatase, although in the normal range, was higher in patients with greater bone loss. A higher BMI is normally associated with a higher BMD $(4,5,12)$, and this is observed in premenopausal and even in younger women (13). In adults, alkaline phosphatase is a well-established indirect marker of bone resorption, and higher values are associated with lower BMD $(5,14)$.

The practice of sports was associated with a higher BMD at the lumbar spine level and tended to be associated with a higher BMD at the femoral neck level, in agreement with previous reports (15).

Smoking and alcohol consumption showed no association with a lower BMD, although both were only moderate in the sample.

Patients with higher femoral BMD had a higher caffeine intake. It is known that high intakes of caffeine are associated with bone loss (16). In this sample, the overall caffeine 
intake was in fact low, and the patients who drank more coffee were those who ate more and were heavier, thus explaining this apparent contradiction. Age is a well-established risk factor for osteoporosis (4), but its effect has mostly been observed in postmenopausal subjects. The finding of a borderline association with lower bone mass in this sample is further evidence that the process of bone loss starts long before menopause. Furthermore, our data show that age per se is not the main determinant of BMD in this subset of patients, and that the other variables hold independent associations with bone loss.

Daily calcium ingestion was less than $800 \mathrm{mg}$ in $52 \%$ of the patients; this is a wellestablished risk factor for a low BMD (17). In fact, stepwise multivariate analysis showed that a lower calcium ingestion was associated with lower BMD at L1 and L2-L4. A higher calcium intake has been recommended starting during adolescence as a preventive measure $(6-8,17)$. In the present patient sample, all drugs and systemic conditions known to be associated with bone loss were excluded. Since all of these women had regular menses and normal estrogen levels, the highly significant association of estrogen deficiency with osteoporosis was ruled out. Therefore, the only known major risk factor remaining in this study population was low calcium ingestion $(4,8)$. A reduced BMD observed cross-sectionally is either the result of bone mass loss, or reflects a lower than expected peak of bone mass achieved during adulthood $(1,4)$. Since our patients did not present the factors known to be associated with bone loss, the lower BMD observed may indicate a lower peak of bone mass, and this in turn may be related to deficient calcium intake.

Finally, it should be pointed out that a selection bias could not be excluded in this study. Socioeconomic and educational factors may have contributed to some of the findings. This study should be extended to other social strata in order to determine whether these findings are confined to a certain class or represent a generalized phenomenon in our population.

Our data show that in 40-50-year old premenopausal women a higher than expected frequency of low BMD was associated with lower calcium intake, relatively less physical activity, and lower BMI. This clearly indicates that the classical risk factors are operative before the cessation of menses occurs, and that their effect may be independent of estrogen levels, most likely leading to a lower bone mass peak during early adult life.

\section{Acknowledgments}

Special thanks are due to Prof. Sídia Jaques for statistical advice, to Izabel B. Streit for the dietary analysis, to Laboratório Weinmann for hormonal and biochemical determinations, and to Radimagem for the densitometric studies.

\section{References}

1. Riggs BL \& Melton III LJ (1986). Involutional osteoporosis. New England Journal of Medicine, 314: 1676-1686.

2. Riggs BL \& Melton III LJ (1992). The prevention and treatment of osteoporosis. New England Journal of Medicine, 327: 620-627.

3. Prior JC, Vigna YM, Schechter MT \& Burgess AE (1990). Spinal bone loss and ovulatory disturbances. New England Journal of Medicine, 323: 1222-1227.
4. Cummings SR, Nevitt MC, Browner WS, Stone K, Fox KM, Ensrud KE, Cauley J, Black D \& Vogt TM (1995). Risk factors for hip fractures in white women. New England Journal of Medicine, 332: 767-773.

5. Christiansen C \& Riis BJ (1989). New methods for identifying "at risk" patients for osteoporosis. Clinical Rheumatology, 8: 52-55.
6. Holbrook TL, Barret-Connor E \& Wingard DL (1988). Dietary calcium and risk of hip fracture: 14-year prospective population study. Lancet, II: 1046-1049.

7. Cauley JA, Gutai JP, Kuller LH, Le Donne D, Sandler RB, Sashin D \& Powell JG (1988). Endogenous estrogen levels and calcium intakes in postmenopausal women. Journal of the American Medical Association, 260: 3150-3155. 
8. Baran D, Sorensen A, Grimes J, Lew R, Karellas A, Johnson B \& Roche J (1990). Dietary modification with dairy products for preventing vertebral bone loss in premenopausal women: A three-year prospective study. Journal of Clinical Endocrinology and Metabolism, 70: 264-270.

9. Marshall D, Johnell O \& Wedwl H (1996). Meta-analysis of how well measures of bone mineral density predict occurrence of osteoporotic fractures. British Medical Journal, 312: 1254-1259.

10. Burke B (1947). The dietary history as a tool in research. Journal of the American Dietary Association, 23: 1041-1046.

11. Williet WC (1994). Future directions in the development of food-frequency questionnaires. American Journal of Clinical Nutrition, 59 (Suppl): 1715-1745.
12. Reid IR, Ames $R$, Evans MC, Sharpe $S$, Gamble G, France JT, Lim TMT \& Cundy TF (1992). Determinants of total body and regional bone mineral density in normal post menopausal women: a key role for fat mass. Journal of Clinical Endocrinology and Metabolism, 75: 45-51.

13. Drinkwater $B L$, Bruemner BS \& Chesnut $\mathrm{CH}$ (1990). Menstrual history as a determinant of current bone density in young athletes. Journal of the American Medical Association, 263: 545-548.

14. Christiansen C, Riis BJ \& Rodbro P (1987). Prediction of rapid bone loss in postmenopausal women. Lancet, 16: 1105-1108.
15. Prince RJ, Smith $M$, Dick IM, Price RI, Webb PG, Henderson NK \& Harris MM (1991). Prevention of postmenopausal osteoporosis: a comparative study of exercise, calcium supplementation, and hormone replacement therapy. New England Journal of Medicine, 325: 1189-1195.

16. Kiel DP, Felson DT, Hannan MT, Anderson JJ \& Wilson PWF (1990). Caffeine and the risk of hip fracture: The Framingham study. American Journal of Epidemiology, 132: 675-684.

17. Picard D, Ste-Marie LG, Coutu D, Carrier $L$, Chartrand $R$, Lepage R, Fugère $P$ \& D'Amour P (1988). Premenopausal bone mineral content relates to height, weight and calcium intake during early adulthood. Bone and Mineral, 4: 299-309. 